\title{
CRAVEIRO-DA-INDIA: CARACTERÍSTICAS FÍSICAS DAS SEMENTES E SEUS EFEITOS NA GERMINAÇAO E DESENVOLVIMENTO VEGETATIVO (')
}

\author{
JOCELY ANDREUCCETTI MAEDA (2), MARILENE LEĀO ALVES BOVI (3, 5), \\ ODAIR ALVES BOVI $(4,5)$ e ANTONIO AUGUSTO DO LAGO $(2,5)$
}

\begin{abstract}
RESUMO
Sementes de craveiro-da-India foram classificadas quanto ao tamanho, cor e densidade, a fim de avaliar seu efeito na germinaçăo em laboratório e na emergência e desenvoivimento das mudas em viveiro. As sementes grandes (média de $2,49 \mathrm{~g} /$ semente) tiveram maiores porcentagens de germinação e emergência, produziram plantas de maior altura e rafzes principais mais longas quando comparadas às sementes pequenas (média de $1,33 \mathrm{~g} / \mathrm{semente)}$. As sementes claras (imaturas) apresentaram comportamento inferior às escuras (maduras) em testes de laboratório e viveiro. Por sua vez, as sementes leves mostraram comportamento inferior ao das pesadas apenas em testes de laboratório, sem reflexos na emergência e no desenvolvimento das mudas em viveiro. Dessa maneira, não se recomenda o uso de sementes claras e pequenas para produção de mudas.
\end{abstract}

Termos de indexação: craveiro-da fndia, Syzygium aromaticum. semente, geminaçăo, emergência, desenvolvịmento vegetativo.

\section{ABSTRACT \\ CLOVER TREE: SEED CHARACTERISTICS AND THEIR EFFECTS ON GERMINATION AND SEEDLING DEVELOPMENT}

Seeds of clove tree (Syzygium aromaticum (L.) Merr. et Perry) were separated by size, density and color. Germination, emergence, and seedling growth were determined on each fraction under laboratory and nursery conditions. Larger seeds $(2.49 \mathrm{~g} / \mathrm{seed})$ had superior germination,

(1) Recebido para publicaçăo em 12 de fevereiro $\theta$ aceito em 6 de abril de 1990.

(2) Seçáo de Sementes, instituto Agronómico (IAC), Caixa Postal 28, 13001 Campinas (SP).

(3) Seçăo de Plantas Tropicais, LAC.

(4) Seçáo de Plantas Aromáticas e Fumo، IAC.

(5) Com bolsa de pesquisa do CNPq. 
emergence and speed index than smaller ones. Seedlings from larger seeds were $30 \%$ taller and their main roots lenght were $30 \%$ longer when compared to seedlings from the smaller seeds $(1,33 \mathrm{~g} / \mathrm{seed})$. Light colored seeds (imature) were interior in all the studied aspects compared to dark colored ones. Lighter weight seeds showed similar results in emergence and seedling growth compared to the heavier fraction. Small and light colored seeds should not be recommended for sowing.

Index terms: clove, Syzygium aromaticum seeds, germination, emergence and seedling growth.

\section{INTRODUÇÃO}

O craveiro-da-índia pertence à família Myrtaceae, que conta com cerca de 3.000 espécies de árvores e arbustos tropicais e subtropicais. Seu nome científico varia com a classificação adotada; mais recentemente, foi classificado como Syzygium aromaticum (L.) Merr. et Perry, existindo, porém, várias citaçōes anteriores, a saber. Eugenia caryophyllus (Sprengel) Büllock et Harrison, Caryophyllus aromaticus L., Eugenia caryophyllata Tumb e Eugenia aromatica (L.) Baill.

O conhecimento do cravo e o seu uso datam de época muito remota, sendo a espécie originária das ilhas Molucas, especialmente de regiőes vulcânicas. O craveiro-da-índia, cuja principal finalidade comercial reside nos botões florais, especiaria de grande valor nos mercados mundiais, tem ainda propriedades anti-sépticas e analgésicas, sendo seu óleo muito aplicado na odontologia (SANTOS, 1942). Segundo CARDOSO (1974), seu comércio torna-se ainda mais interessante por se tratar de produto não perecivel. A Indonésia e a Tanzânia produzem e utilizam grandes quantidades de cravo para as suas indústrias de cigarro (WAARD, 1974; WT, 1969). Além disso, a própria árvore pode ser utilizada com fins ornamentais, pois apresenta rara beleza quando surgem as folhas novas, brilhantes e avermelhadas. A duração dessa planta tropical é, conforme SANTOS (1942), de mais de meio século, podendo-se encontrar exemplares com mais de cem anos (WT, 1969).

Entre os métodos de propagação do craveiro, o plantio de sementes constitui o único processo prático e econômico para a obtenção de mudas em grande escala (CUNHA, 1950; FIGUEIREDO, 1934; WAARD, 1974). Essa semente, botanicamente fruto, é do tipo drupa, elíptica, semelhante à azeitona, formada por uma parte externa carnosa, em cujo interior se acha um embrião com dois cotilédones, e que, segundo CUNHA (1950), nāo é necessário colher da árvore; é preferivel que ela os deixe cair, o que acontece após quatro meses da abertura das flores. No entanto, nem todas as sementes caídas săo boas para plantar. Umas são imperfeitas, maldesenvolvidas, outras não completaram a maturação ou são muito pequenas. É necessário então conhecer o melhor material a ser selecionado, pois este varia em tamanho, peso e cor. 
O poder germinativo dessas sementes é de curta duração, sendo preciso, portanto, que o plantio se efetue quase imediatamente depois da colheita. FARRANT et al. (1988) classificaram as sementes de espécies do gênero Syzygium como altamente recalcitrantes. Sua germinaçāo inicia-se imediatamente após atingir a maturidade, sem ocorrência de dorméncia, e o processo germinativo se dá rapidamente, mesmo na ausência de água adicional. De forma geral, tais sementes parecem suportar muito pouco o dessecamento e perdem com rapidez a viabilidade quando há um decréscimo no conteúdo de umidade abaixo de um valor relativamente alto. São plantas próprias de regiōes tropicais, onde há umidade suficiente para que a germinação se processe durante todo 0 ano. Normalmente, sementes dessas plantas apresentam também sensibilidade à baixa temperatura.

Apesar do longo tempo em que o craveiro-da-india é explorado economicamente, as informaçōes relativas a germinação, emergência, desenvolvimento inicial e outros aspectos tecnológicos de suas sementes são ainda muito incompletas. As próprias Regras Nacionais para Análise de Sementes (BRASIL, 1980), bem como as internacionais (ISTA, 1985), são omissas com relação ao craveiro-da-India, não só quanto à temperatura como a outras condiçōes para a execução do teste de germinaçāo.

O relato mais completo encontrado, até então, sobre germinação e formação de mudas dessa especiaria é fornecido por CUNHA (1950). Nele é recomendado que, após a colheita, os frutos sejam embebidos em água durante dois a três dias para facilitar a remoção dos embriōes da casca (pericarpo + tegumento) sem danificá-los; apertando-se o fryto entre os dedos, o embriāo separa-se facilmente da casca polposa envolvente. FIGUEIREDO (1934) já havia comentado sobre a necessidade de retirada da casca dos frutos. CUNHA (1950) recomenda também que, depois de descascados, sejam aproveitados somente os embriōes com cotilédones de cor verde-oliva e com radícula bem desenvolvida e clara; os que tiverem os cotilédones avermelhados ou radícula com a extremidade preta devem ser descartados.

Segundo WT (1969), a duraçāo do processo germinativo dessas sementes está entre 28 e 42 dias. Por sua vez, CUNHA (1950) relata que a germinação de sementes descascadas (embriões) se processa após 35 dias, enquanto a germinação de unidades inteiras ocorre somente depois de 60 dias da semeadura. Porcentagens finais de germinaçāo entre 70 e 80 foram relatadas por WT (1969), enquanto CUNHA (1950) cita que se obtém $85 \%$ de germinação partindo de sementes descascadas e, $74 \%$, quando de frutos inteiros.

Quanto ao estádio de maturidade e formaçāo das sementes, CUNHA (1950) comenta que 40 a $50 \%$ das sementes colhidas são refugadas por maturação incompleta, má conformação e tamanho abaixo da média. No entanto, 
nenhuma relação entre tamanho, grau de maturidade e densidade de sementes dessa espécie e o desenvolvimento posterıor das mudas obtidas pode ser encontrada na literatura.

O objetivo do presente trabalho de pesquisa foi estudar os efeitos do tamanho, da cor e da densidade dos frutos na germinação de sementes de craveiro-da-india em laboratório, e na emergência e desenvolvimento das mudas em viveiro.

\section{MATERIAL E MÉTODOS}

As sementes de craveiro-da-india utilizadas neste estudo eram provenientes da Estação Experimental de Pariqueraçu, do Instituto Agronômico de Campinas. Após a colheita, o material foi embalado em saco plástico para evitar perdas de umidade e, após homogeneizaçāo e eliminaçāo manual de material estranho e impurezas, submetido à classificação seguinte:

\subsection{Tamanho das sementes}

Nas sementes divididas, visualmente, em grandes, médias e pequenas, avaliou-se a proporção em peso de cada fraçáo em relação à amostra original, determinando-se o peso por semente em cada fração e o teor de umidade. Em seguida, cada fração, inclusive a original, foi submetida aos testes de germinação e velocidade de germinação em laboratório, assim como de emergência, indice de velocidade e avaliação de altura de planta, número de folhas, circunferência do coleto, comprimento da raiz principal e peso seco da parte aérea e das raizes, quando as plantas completaram doze meses em viveiro.

\subsection{Cor das sementes}

As sementes foram classificadas, visualmente, em claras (avermelhadas) e escuras (quase pretas). Em cada uma dessas duas fraçōes, determinaram-se os valores de germinaçāo, emergência, velocidade de emergência e caracteristicas do desenvolvimento vegetativo das plantas.

\subsection{Densidade das sementes}

As sementes foram colocadas em água, considerando-se "leve" a fração que flutuava e, "pesada", aquela que ficava no fundo do recipiente. Com essas frações, efetuaram-se as mesmas avaliaçōes realizadas para cor das sementes.

Observando 0 alto teor de umidade inicial das sementes e tratando-se de espécie recalcitrante (FARRANT et al., 1988), que não suporta três dias de armazenamento (WIT, 1969), o preparo, a classificação e a instalação dos testes foram efetuados imediatamente após a colheita.

Classificadas, nas diferentes frações, por tamanho, cor e densidade, as sementes permaneceram por 48 horas em água e, em seguida, com uma leve pressāo do fruto entre os dedos, separou-se facilmente o embriāo, eliminando-se 
o pericarpo e o tegumento. Os embrióes foram, em seguida, lavados, tratados com o fungicida Rhodiauram ( $3 \mathrm{~g} / \mathrm{kg}$ semente) e encaminhados para os diferentes testes.

Em todas as avaliaçōes, utilizaram-se cinco repetiçōes de 50 sementes cada uma e efetuaram-se contagens no teste de germinação aos $7,14,21$ e 28 dias, com a contagem final aos 35 dias após a semeadura. $O$ substrato usado foi o rolo de pano, e, a temperatura do germinador, a alternada $20-30^{\circ} \mathrm{C}\left(20^{\circ} \mathrm{C}\right.$ por 16 horas $\theta 30^{\circ} \mathrm{C}$ por 8 horas), considerada como ideal em trabalho que avaliou diferentes temperaturas de germinação para esta espécie (MAEDA et al. ${ }^{6}$ ).

Para determinar o índice de velocidade de germinaçāo, em laboratório, e de emergência, em condiçōes de viveiro, utilizou-se o método de MAGUIRE (1962), indicado como teste que avalia o vigor da semente, baseando-se no princípio de que quanto mais rapidamente a semente germina, maior é seu vigor.

Para determinar o teor de umidade, empregou-se a estufa elétrica de desidratação, com ventilaçāo adequada, mas não forçada, dotada de controle termostático que permite manter a temperatura a $105 \pm 3^{\circ} \mathrm{C}$. Nessas condiçōes, as sementes permaneceram por 24 horas. A porcentagem de umidade foi calculada para cada amostra, na base do peso úmido, segundo BRASIL. (1980).

Em condições de viveiro, o substrato utilizado, ao qual nāo se incorporou adubo, foi solo com a seguinte composição química $(7): P=21 \mu \mathrm{g} / \mathrm{cm}^{3}$; matéria orgânica $=3,9 \% ; \mathrm{pH}$ em $\mathrm{CaCl}_{2}=5,1 ; \mathrm{K}=0,18 \mathrm{meq} / 100 \mathrm{~cm}^{3} ; \mathrm{Ca}=$ $=4,1 \mathrm{meq} / 100 \mathrm{~cm}^{3} ; \mathrm{Mg}=1,0 \mathrm{meq} / 100 \mathrm{~cm}^{3} ; \mathrm{H}+\mathrm{Al}=2,8 \mathrm{meq} / 100 \mathrm{~cm}^{3} ;$ soma das bases $=5,3 \mathrm{meq} / 100 \mathrm{~cm}^{3}$; capacidade de troca cationica $=8,1 \mathrm{meq} / 100 \mathrm{~cm}^{3}$, e saturação por bases $=65 \%$.

Empregaram-se sacos plásticos pretos de $10 \times 24 \mathrm{~cm}$, cheios com o substrato acima e colocados em viveiro com $50 \%$ de insolação. Na semeadura, colocou-se a semente na horizontal e a $1 \mathrm{~cm}$ de profundidade, irrigando-se os recipientes logo após.

Os tratos culturais resumiram-se a regas diárias e eliminação manual de ervas daninhas.

As avaliaçōes consistiram em contagem semanal do número de plântulas emergidas por parcela: considerou-se emergida aquela que tinha os cotilédones elevados acima do solo e a emissão do primeiro par de folhas. Um ano após a semeadura, realizaram-se mensuraçōes em uma amostra de cinco plantas, tomadas ao acaso, por parcela, avaliando-se os seguintes caracteres:

(6) MAEDA, J.A.; BOVI, M.L.A.; LAGO, A.A. \& BOVI, O.A. Germinação de sementes de craveiro-daIndia: efeito de temperatura, polpa do fruto e tratamento fungicida. Pesquisa Agropecuária Brasileira (No prelo).

(7) Análise efetuada pela Seção de Fertilidade do Solo e Nutrição de Plantas do IAC. 
1) altura da planta $(\mathrm{em} \mathrm{cm})$ : medida desde o coleto até a extremidade da haste central da muda;

2) número de folhas: considerando apenas as folhas vivas (funcionais);

3) circunferência do coleto (em $\mathrm{cm}$ ): medida na região do coleto da planta;

4) comprimento da raiz principal $(\mathrm{em} \mathrm{cm})$ : avaliada desde a região do coleto até a extremidade da raiz principal;

5) peso da parte aérea (em gramas): considerando o peso seco das foIhas e hastes da muda seccionada na regiâo do coleto;

6) peso das raizes (em gramas): levando em conta o peso seco de todas as raizes da muda seccionada na regiáo do coleto.

O delineamento estatístico utilizado para as condiçōes de laboratório e viveiro foi o completamente casualizado. Os dados em porcentagem foram transformados em arco seno $\sqrt{\% / 100}$ para fins de normalizar a sua distribuição. Quando se observou significância do teste $F$, ao nivel de $5 \%$, efetuou-se a comparação entre as médias pelo teste de Tukey ao mesmo nivel (GOMES, 1966).

\section{RESULTADOS E DISCUSSÃO}

Quando as sementes foram classificadás por tamanho, $26,4 \%$ do lote original era constituído de sementes grandes, com um peso médio de $2,49 \mathrm{~g}$ por unidade, e $75 \%$ de teor de umidade (Quadro 1). As médias constituíram-se em $36,2 \%$ do lote original, com peso médio de $2,00 \mathrm{~g}$ por semente e $74,3 \%$ de teor de umidade; e as pequenas correspondiam a $37,4 \%$ do lote original, apresentavam $1,3 \mathrm{~g}$ por semente e $73,7 \%$ de umidade. O lote original compreendia sementes de $2,12 \mathrm{~g}$ cada uma com teor de umidade de $76,2 \%$.

Quando se avaliou o efeito de cada uma dessas frações no seu valor germinativo, notou-se que a velocidade de germinação e a velocidade de emergência não foram afetadas pelo tamanho da semente. Em outras espécies botânicas, estudos semelhantes mostraram que sementes maiores apresentaram indices superiores (AUSTENSON \& WALTON, 1970; RIES \& EVERSON, 1973; FRAZĀO et al., 1983). Entretanto, o valor de germinação final do craveiro-da-índia (35 dias) foi bastante afetado pelo tamanho da semente; as grandes e médias mostraram germinaçāo superior às do lote original e, as pequenas, os menores valores. Resultados semelhantes foram obtidos com outras espécies, quando também classificadas por tamanho (MAEDA et al., 1980, 1987). $\mathrm{Na}$ avaliação desses fatores pelo teste de emergência final em viveiro, as diferenças seguiram os mesmos padrōes: as sementes grandes emergiram significativamente em maior número do que as pequenas e do que o lote original, enquanto as médias não diferiram do lote original nem das sementes grandes, mas foram significativamente superiores às pequenas. 


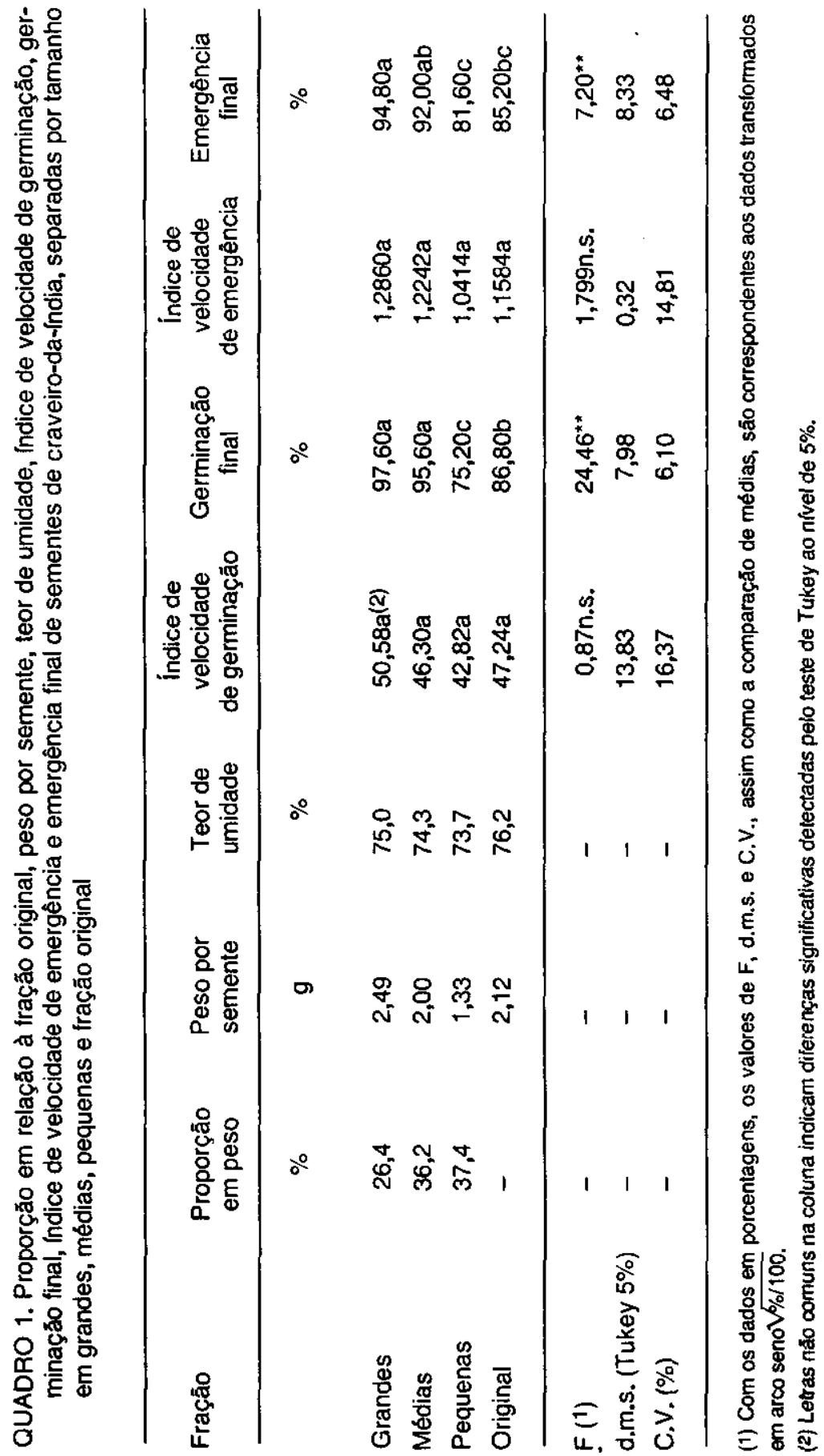


Os altos valores de germinação e emergência observados (entre 75,2 e $97,6 \%$ ) só foram possiveis com o manuseio rápido das sementes antecedendo os testes, pois nos preliminares perdeu-se muito material pela diminuição do seu teor de umidade. Valores entre 70 e $85 \%$ foram reportados anteriormente por CUNHA (1950) e WT (1969).

Quando se avaliou o desenvolvimento vegetativo das plantas oriundas de sementes classificadas por tamanho (Quadro 2), as grandes superaram as pequenas quanto à altura; as plantas originárias de sementes grandes eram, aos doze meses, significativamente mais altas do que as germinadas das pequenas. Por outro lado, as médias não diferiram das grandes e, juntamente com as pequenas, não diferiram do lote original.

$\mathrm{Na}$ avaliação do número de folhas, circunferência do coleto e peso da parte aérea, năo houve diferenças estatísticas significativas quando as plantas eram provenientes de sementes grandes, médias ou pequenas de craveirodaindia.

O comprimento da raiz principal variou com o tamanho da semente que deu origem à planta: quando procedente de semente pequena, era significativamente menor do que aquelas do lote original, que, por sua vez, não diferiu das demais.

Quanto ao peso de raizes, as plantas provenientes de sementes grandes apresentaram maiores valores, diferindo das do lote original.

CUNHA (1950) aconselha descartar as sementes pequenas para fins de plantio. O estudo aqui reportado também constatou que sementes pequenas apresentaram germinação e emergência inferior às demais. Constatou ainda um efeito entre tamanho de semente e altura da planta e comprimento das raízes: sementes pequenas propiciaram mudas com menor altura do que sementes grandes e com comprimento de raiz principal inferior ao obtido pelo lote original. Embora para o craveiro-da-índia não existam trabalhos correlacionando desenvolvimento vegetativo em viveiro com precocidade e produção em condiçöes de campo, para uma série de outras plantas tropicais a literatura revela uma influência marcante entre esses caracteres. ASCENSO (1963) e MARIANO (1966), por exempo, relataram que a altura da muda de cacaueiro está diretamente relacionada à sua produçăo futura. Também em seringueira foi reportado o efeito de caracteres de viveiro, tais como a altura e circunferência da planta na produção de látex em condiçōes de campo (FERWERDA, 1969). Em vista do possivel efeito que sementes pequenas possam ter no desenvolvimento e produção do craveiro-da-índia, caso siga, como é de supor, o modelo de desenvolvimento vegetativo relatado para espécies perenes tropicais, das quais fornecemos acima apenas dois exemplos, concorda-se com a opinião já expressa por CUNHA (1950), segundo a qual é aconselhável descartar as sementes pequenas, mesmo considerando que elas representam $37,4 \%$ dos frutos colhidos. 


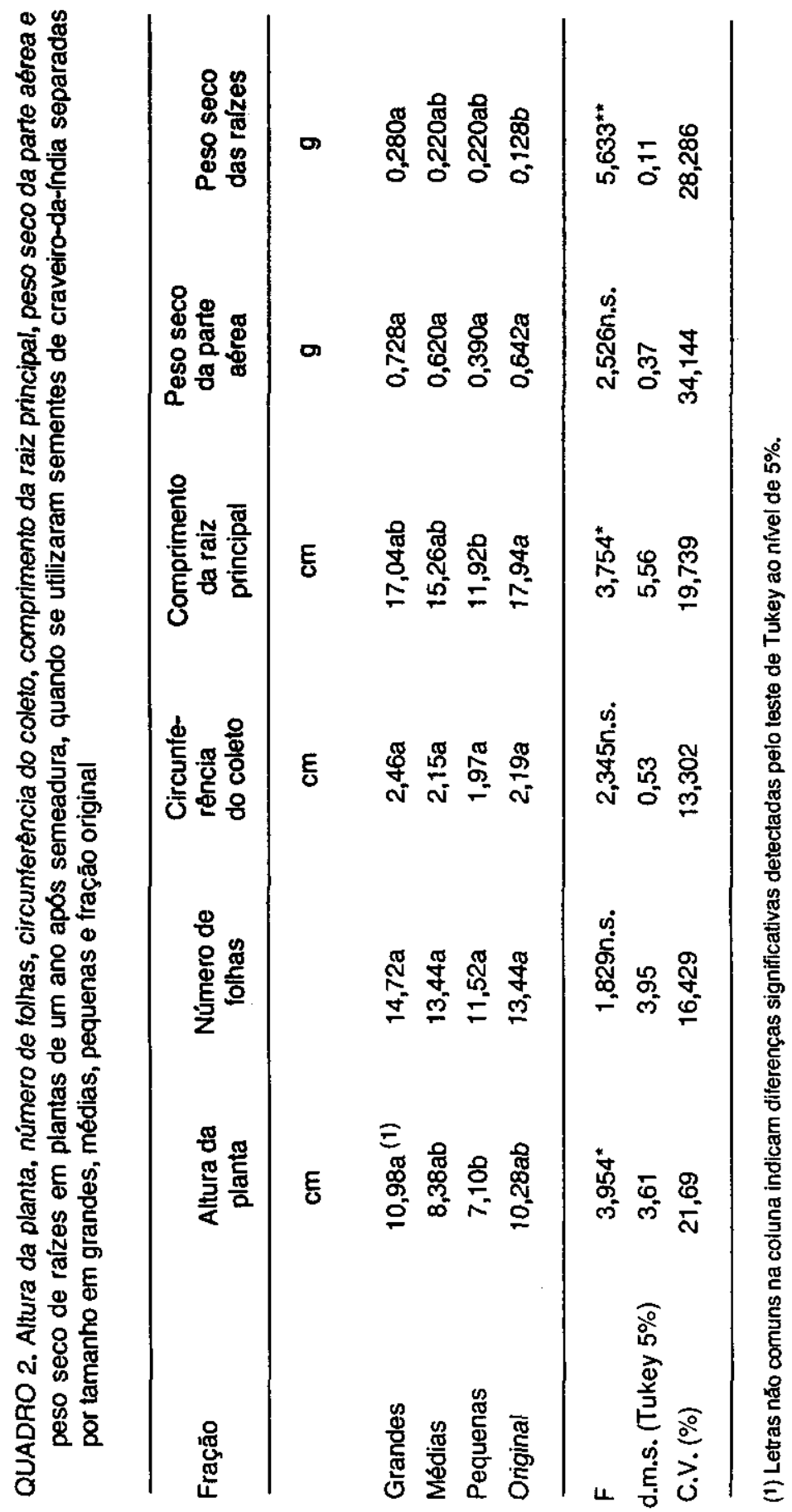


J.A. MAEDA of al.

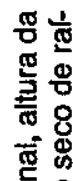

要品

类

通

हाँ

(5)

类

웡

응

당

응은

응

응

응 응 응

政

은

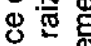

음

응

또읃 땐

을

웅

吨

등

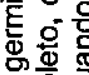

낭

.8.

땡요

. 흠

है잉

的

嗐

동

음음

은

政

잉흐름

응 웡

$\therefore$ 은

要要

ल.

每

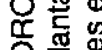

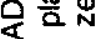

梁

8

\section{- II}

$$
\begin{aligned}
& \text { (a) }
\end{aligned}
$$

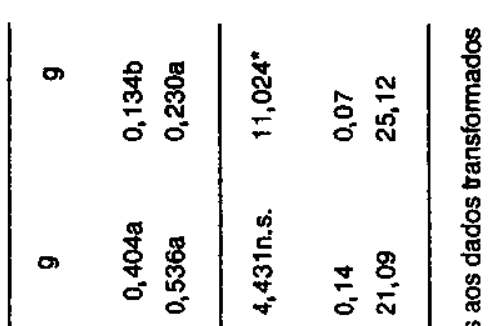$$
\text { . }
$$

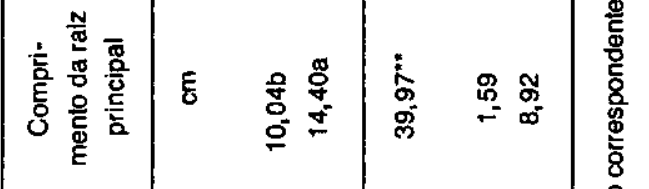

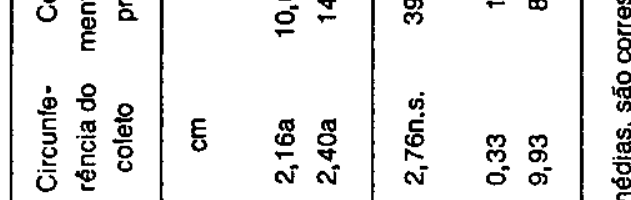

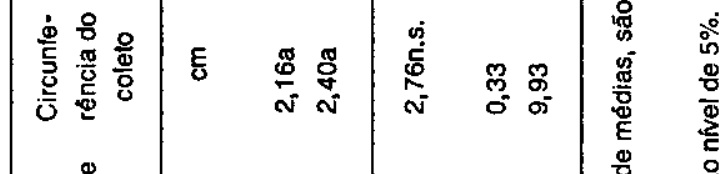

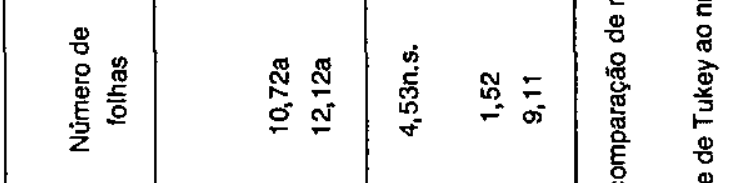$$
\text { (1) }
$$

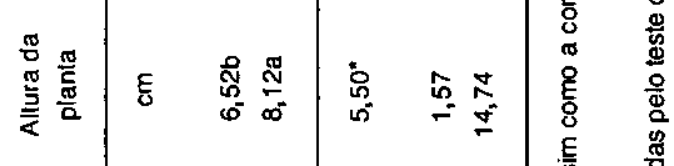

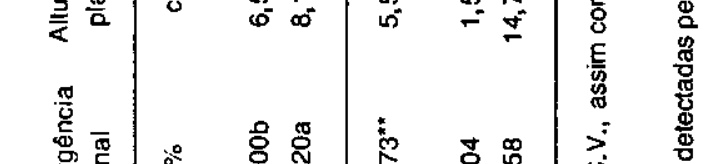

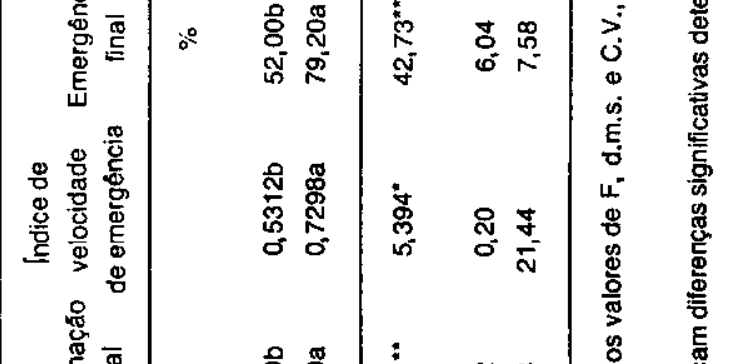$$
\text { ชิ }
$$ 


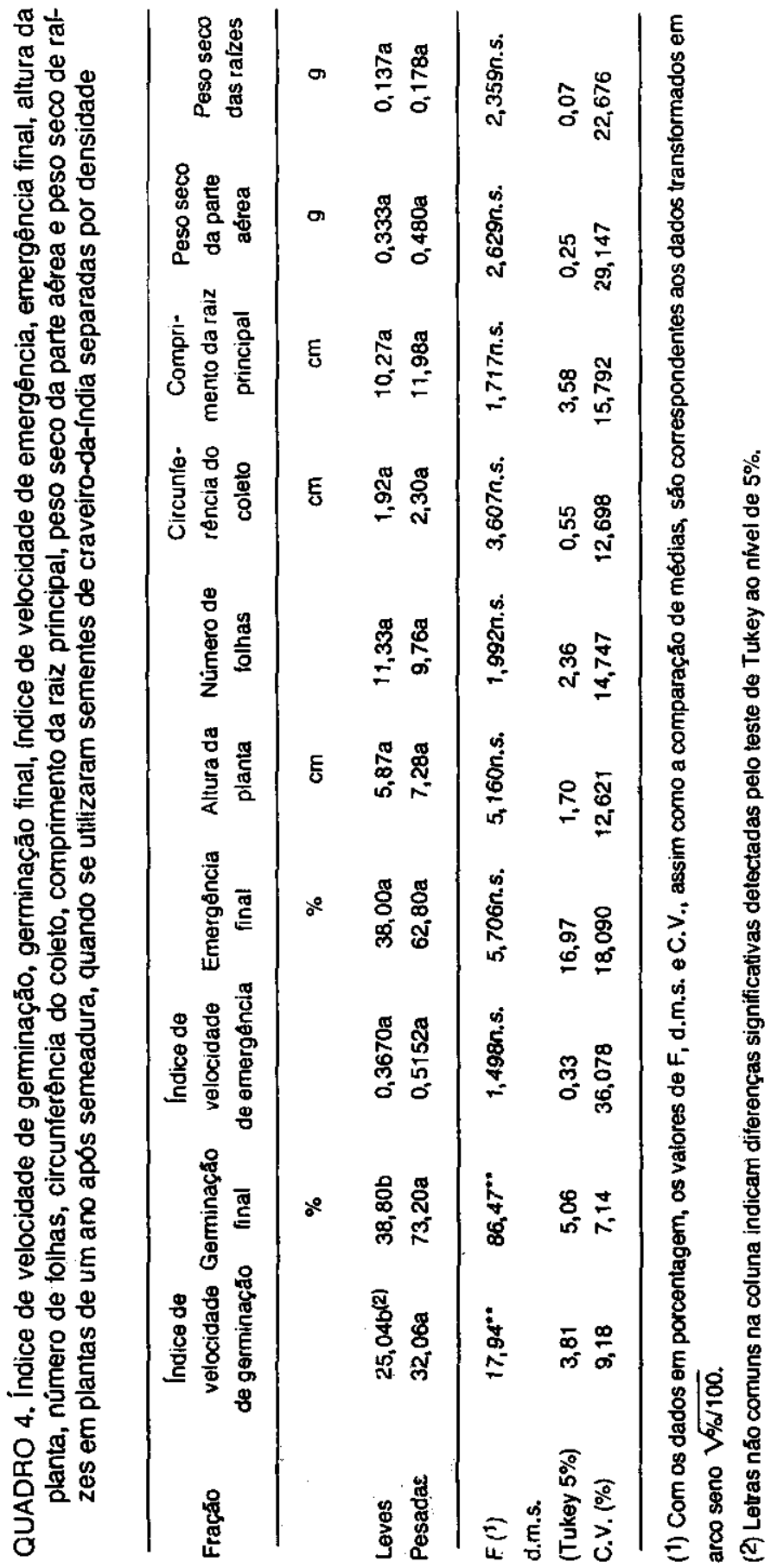


Quando as sementes foram classificadas por cor (Quadro 3), foi significativa a superioridade da escura (madura) sobre a clara (imatura) na germinação final, na velocidade de emergência, na emergência final e mesmo no desenvolvimento vegetativo das plantas originárias dessas sementes, como na altura das plantas, no comprimento da raiz principal e no peso das raizes. Resultados semelhantes foram obtidos para outras culturas (MAEDA et al., 1984, LIN, 1986), onde se reporta que a maturidade do fruto aumenta a qualidade das sementes. Por outro lado, a discriminação por cor em craveiro-da-índia náo mostrou efeito significativo quanto à velocidade de germinação, número de folhas, circunferência do coleto e peso da parte aérea.

Uma vez jue as sementes claras significam estádio anterior à maturidade e, portanto, é muito pequena a porção destas que se solta da árvore por ocasiäo da colheita, e sendo a separação de claras e escuras uma tarefa fácil e não tão demorada, aconselha-se o descarte das sementes imaturas no plantio, tal como sugeriu CUNHA (1950).

Quando foram classificadas pela densidade - Quadro 4 - as sementes que flutuavam na água germinaram mais lentamente em laboratório e apresentaram um valor de germinaçāo final inferior à fraçāo pesada. No entanto, em condiçōes de viveiro, não houve diferenças estatísticas significativas tanto na velocidade de emergência como na emergência final e em todas as demais avaliações de desenvolvimento vegetativo das plantas. Conclui-se, portanto, que a separação em sementes leves e pesadas não se mostrou necessária em condiçōes normais de formação de mudas de craveiro-da-índia. Dessa maneira, embora seja muito fácil a separação das sementes leves, pois já existe a necessidade da embebiçăo dos frutos em água antes do plantio (para a remoção da casca), essa operação se mostrou, pelos testes efetuados em viveiro, dispensável, contribuindo com o maior aproveitamento do material coletado.

\section{CONCLUSÕES}

1. A porcentagem final de germinação e de emergência de sementes grandes de craveiro-da-índia foi bastante superior às de sementes pequenas e às do lote original.

2. As plantas originadas de sementes grandes diferenciaram-se significativamente das de sementes pequenas quanto à altura da planta.

3. As plantas oriundas de sementes grandes apresentaram peso de raizes maiores que as do lote original e, as de sementes pequenas, menores que as do lote original quanto ao comprimento da raiz principal.

4. As sementes claras de craveiro-da-índia, constituindo frutos imaturos, apresentaram comportamento bem inferior às escuras, em testes de laborató rio e viveiro, o que leva a indicar seu descarte no plantio. 
5. Não há necessidade de eliminar as sementes leves de craveiro-daindia, uma vez que elas só diferiram das pesadas em testes de laboratório, sem nenhum reflexo significativo nos testes em condições de viveiro.

\section{REFERÊNCIAS BIBLIOGRÁFICAS}

ASCENSO, J.C. Inheritance and relationships among growth characters of young cacao seedlings. Lisboa, Junta de Investigaçర̄es do Ultramar, 1963. 89p.

AUSTENSON, H.M. \& WALTON, P.D. Relationships between initial seed weight and mature plant characters in spring wheat. Canadian Joumal of Plant Sciences, Ottawa, 50(1):53-58, 1970.

BRASIL. Ministério da Agricultura. Departamento Nacional de Produção Vegetal. Divisão de Sementes e Mudas. Regras para análise de sementes. Braslia, 1980. $188 \mathrm{p}$.

CARDOSO, M. O craveiro-da-findia (Cariophyllus aromaticus L.). O Agronómico, Campinas, 26(1):25-30, 1974.

CUNHA, J.F. Craveiro da Índia (Eugenia caryophyllata Thumb.). São Paulo, Secretaria de Agricultura do Estado. Diretoria de Publicidade Agricola, 1950. 82p.

FARRANT, J.M.; PAMMENTER, N.W. \& BERJAK, P. Recalcitrance - a current assessment. Seed Science and Technology, Zürich, 16(1):155-166, 1988.

FERWERDA, F.P. Rubber (Hevea brasiliensis (Wild.) Müll. Arg.) In:-__ \& WIT, F., eds. Outines of perennial crop breeding in the tropics. Wageningen, $\mathrm{H}$. Veenman \& Zonen, 1969. p.427-458. (Miscellaneous papers, 4)

FIGUEIREDO, E.R. Cultura do craveiro da índia (Caryophyllus aromaticus L.). Săo Paulo, Chácaras e Quintais, 1934. 12p. (Bibliotheca Agrícola Popular Brasileira: especiahias, 2).

FRAZĀO, D.A.C.; FIGUEIREDO, F.J.C.; CORREA, M.P.F.; OLIVEIRA, R.P. \& POPINIGIS, F. Tamanho da semente de guaraná e sua influência na emergência e no vigor. Revista Brasileira de Sementes, Brasnia, 5(1):81-91, 1983.

GOMES, F.P. Curso de estatística experimental. 3.ed. Piracicaba, Escola Superior de Agricultura "Luiz de Queiroz", 1966. 404p.

INTERNATIONAL Seed Testing Association (ISTA), International rules for seed testing 1985. Seed Science and Technology, Zürich, 13(2):299-520, 1985.

LIN, S.S. Efeito do tamanho e maturidade sobre a viabilidade, germinação e vigor do fruto de paimiteiro. Revista Brasileira de Sementes, Braslia, 8(1):57-66, 1986.

MAEDA, J.A.; NUCCI, T.A.; LAGO, A.A. \& ZINK, E. Germinaçăo de sementes da palmeira Archontophoenix alexandrae. In: ENCONTRO NACIONAL SOBRE ARBORIZAÇÄO URBANA, 2., Maringá, 1987. Anais. Maringá, 1987. p.99-107.

; PASSOS, F.A. \& BERNARDI, J.B. Influéncia da cor e do tamanho no vigor de sementes de quiabo. II. Testes de laboratónio. Revista Brasileira de Sementes, Brasilia, 2(2):99-107, 1980. 
MAEDA, J.A.; PEREIRA, M.F.D.A. \& TERRA, M.M. Efeito do estádio de desenvolvimento do fruto sobre a qualidade da semente do cultivar Patricia de videira. Bragantia, Campinas, 43(2):659-666, 1984.

MAGUIRE, J.D. Speed of germination - aid in selection and evaluation for seedling emergence and vigor. Crop Science, Madison, 2(2):176-177, 1962.

MARIANO, A.H. Relaciones entre algunas medidas de vigor y producción en cacao. Turrialba, Instituto Interamericano de Ciências Agricolas, 1966. 41p. Tese (Mestrado)

RIES, S.K. \& EVERSON, E.H. Protein content and seed size retationships with seedling vigor of wheat cultivars. Agronomy Journal, Madison, 65(6):884-886, 1973.

SANTOS, E. Craveiro da Índia. O Campo, Rio de Janeiro, 13(153):18, 1942.

WAARD, P.W.F. The development of clove bads and causes of irregular bearing of cloves (Eugenia caryophyllus (Sprengel) Büllock et Harrison). Joumal of Plantation Crops, Kasagarod, 2(2):23-31, 1974.

WIT, F. The clove tree (Eugenia caryophyllus (Sprengel) Bullock et Harrison). In: FERWERDA, F.P. \& WIT, F., eds. Outlines of perennial crop breeding in the tropics. Wageningen, H. Veenman \& Zonen, 1969. p.163-175. (Miscellaneous papers, 4) 